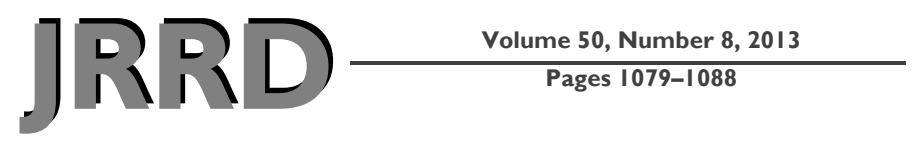

\title{
Comparison of two impression techniques for auricular prosthesis: Pilot study
}

\author{
Kasim Mohamed, MDS; ${ }^{*}$ U. M. Mani, MDS; M. K. Seenivasan, MDS; A. K. Vaidhyanathan, MDS; \\ P. T. Veeravalli, MDS \\ Department of Prosthodontics and Implantology, Faculty of Dental Sciences, Sri Ramachandra University, Chennai, \\ Tamilnadu, India
}

\begin{abstract}
The purpose of this article was to compare the accuracy of a new impression technique, the triple-layer impression technique (TLIT), with the conventional impression technique (CIT) to fabricate an auricular prosthesis. Fifteen male subjects (aged 22-45 yr) were selected. Ten markings were made on the subject's ear (super aurale [sa], sub aurale [sba], pre aurale [pra], post aurale [poa], A, A1, B, B1, C, and C1) and five measurements (sa-sba, pra-poa, A-A1, B-B1, and C-C1) were made. Custom-made trays were used to record impression in CIT and TLIT. Impressions were made using alginate, and models were cast with type IV gypsum product. Markings were transferred on the cast. Measurements were rechecked on the models. Distribution analysis of difference in measurements between the two impression techniques and the subject's actual values was evaluated. Sign test was used to analyze the statistical significance. Statistically significant differences were found in measurements A$\mathrm{A} 1, \mathrm{~B}-\mathrm{B} 1$, and $\mathrm{C}-\mathrm{C} 1$ between the two techniques when compared with the subject's actual dimensions $(p<0.01)$. TLIT was found to produce accurate models when compared with CIT. The TLIT used in the study was cost effective, less technique sensitive, and tailor made to reduce chairside orientation time during wax try-in appointments for rehabilitating patients, especially those with unilateral auricular defects.
\end{abstract}

Key words: accuracy, auricular prosthesis, conventional impression technique, distortion, ear anthropometry, ear measurement, ear orientation, sculpting, triple-layer impression technique, unilateral.

\section{INTRODUCTION}

Auricular defects can be caused by several conditions, such as trauma, congenital malformation, or surgical removal of a neoplasm [1]. Repairs using autogenous tissue are the gold standard in the rehabilitation of these defects; however, rehabilitation with aesthetic prostheses may be a suitable treatment alternative in patients for whom a repair with autogenous tissue is not possible. Orientation of the ear prosthesis is critical to achieve, especially in a unilateral missing ear. Impression techniques play a vital role in accurate reproduction of the affected and unaffected ears, orientation of the ear during wax try-in, and fabrication of ear prostheses. Several impression techniques are described in the literature, including using plaster in a two-piece mold, reversible

\footnotetext{
Abbreviations: CIT = conventional impression technique, $\mathrm{CT}=$ computerized tomography, LS = laser scan, $\mathrm{MRI}=$ magnetic resonance imaging, poa $=$ post aurale, pra $=$ pre aurale, $\mathrm{sa}=$ super aurale, sba $=$ sub aurale, TLIT $=$ triple-layer impression technique.

*Address all correspondence to Kasim Mohamed, MDS; Department of Prosthodontics and Implantology, Faculty of Dental Sciences, Room 8, Sri Ramachandra University, Porur, Chennai, Tamilnadu, India, 600116; 0044-2476-8027; fax: 0044-592-8643. Email: mohamedkasim9@yahoo.com http://dx.doi.org/10.1682/JRRD.2012.08.0145
} 
hydrocolloid enclosed by a wax collar, irreversible hydrocolloid contained in a wax or thermoplastic ring, irreversible hydrocolloid in a rigid tray, and the conventional impression technique (CIT) [2].

Impression materials used for auricular impression are alginate, vinyl polysiloxane, and polyether [3-5]. In the CIT, an irreversible hydrocolloid supported by a rigid tray is used to record auricular impression. Reproducibility of the auricular impression apart from impression material depends on various factors but primarily on patient position during impression making. Although the CIT is less technique sensitive and less time consuming, having the patient lie on one side can cause distortion of the soft tissue contours from the weight of the impression material against the skin [6]. Thus, the success depends on the use of a proper impression technique, apart from the maxillofacial prosthetic skill and artistry [7]. The aim of this study is to evaluate whether a new impression technique (triple-layer impression technique [TLIT]) will reduce ear distortion when compared with the CIT, especially for unilateral auricular prostheses.

\section{MATERIALS AND METHODS}

Fifteen male subjects were selected, and written consent to participate in the study was obtained. Institutional ethical committee clearance was obtained to conduct the study. The volunteers were between 25 and 45 yr old and devoid of any ear malformations. The selection criterion for the study was that the subject's earlobes must be freely movable. The subjects were instructed to have their hair cut so that the hairline was above the superior margin of the ear to enable the operator to identify and place the margins for measurements. Two impression trays were fabricated using cold cure acrylic resin (DPI-RR Cold Cure, Dental Products India; Mumbai, India) for the CIT (Figure 1(a)) and TLIT (Figure 1(b)). All impressions were recorded by a single operator.

\section{Measurements and Markings on Ear}

The subjects were seated in a dental chair in an upright position to make the measurements. A marker pen was used to mark the landmarks for pre- and postimpression measurements. Two standard and three additional anthropometric measurements were used in this study. Four points on the super aurale (sa), sub aurale (sba), pre aurale (pra), and post aurale (poa) were marked

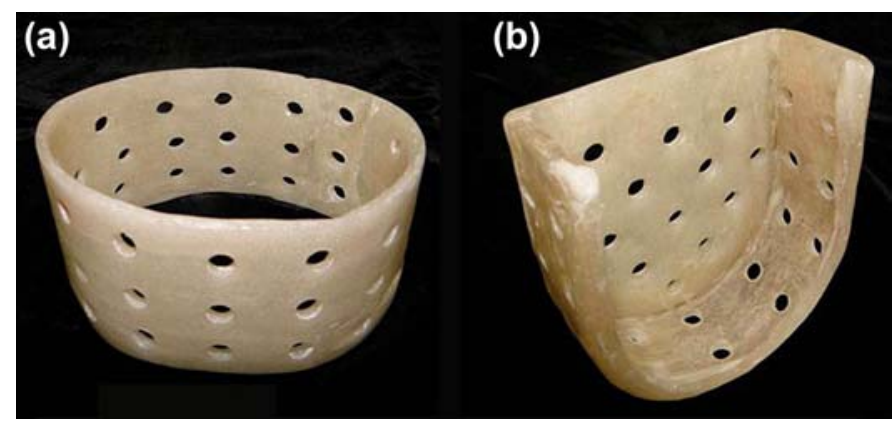

Figure 1.

(a) Custom-made impression tray for conventional impression technique. (b) Custom-made impression tray for triple-layer impression technique.

on the subject's ear [8]. Two measurements, length and width, were measured. The distance between sa and sba denotes the length of the ear, and the distance between pra and poa denotes the width of the ear (Figure 2). Manual anthropometry was used, and measurements were made using digital vernier calipers. Three other points (A, B, and C) were marked on the ear, and three points opposite to these (A1, B1, and C1) were marked (Figure 3). Table 1 explains these landmarks.

Three measurements, the distances between points $\mathrm{A}-\mathrm{A} 1, \mathrm{~B}-\mathrm{B} 1$, and $\mathrm{C}-\mathrm{C} 1$, were measured using a bluntend divider and metal scale in order to prevent any injury to the soft tissue. The values were tabulated. These points, which were marked prior to impression making, and five measurements denoted the subject's actual values. The markings after impression making were transferred onto the impression surface and finally onto the cast. Dimensions on the casts obtained from the CIT and TLIT were compared with the subject's actual values.

\section{Conventional Impression Technique}

The subjects were positioned on the dental chair in a supine position to record impression using CIT [9]. They were instructed to turn their face toward the left side to provide good accessibility. The external acoustic meatus was blocked with a small piece of cotton. The custommade tray ensured that adequate clearance between the tray and ear was present. Alginate (Neocolloid, Zhermack SpA; Badia Polesine, Italy) was manipulated and applied to the internal surface of the ear and poa region. The remaining alginate filled three-fourths of the tray. After the initial set of alginate, the superior one-third of the tray 


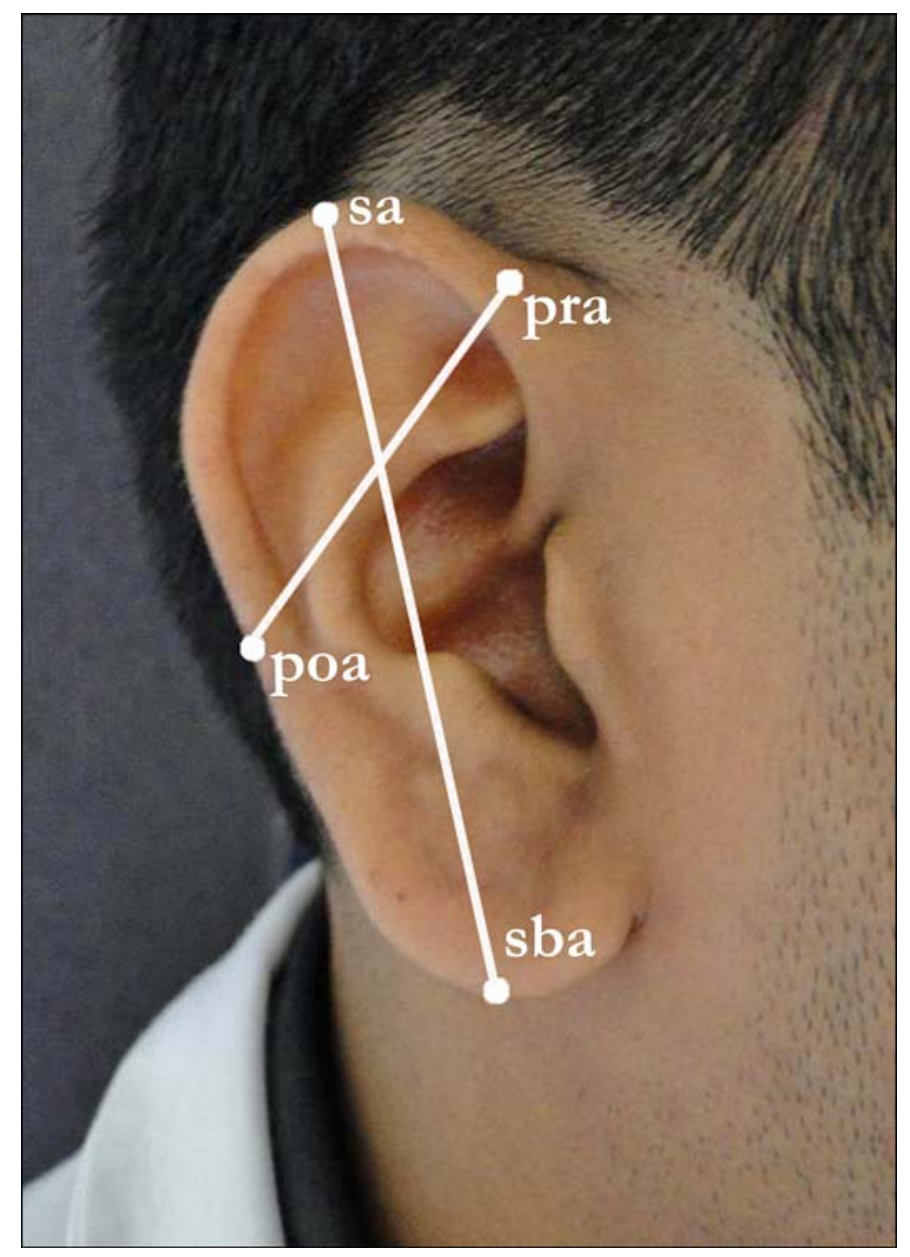

Figure 2.

Landmarks to measure length and width of ear. poa $=$ post aurale, pra $=$ pre aurale, $\mathrm{sa}=$ super aurale, sba $=$ sub aurale.

was filled with dental plaster. The tray was retrieved when the plaster was set. We ensured that the markings were transferred onto the impression surface. The subjects were allowed to relax for $1 \mathrm{~h}$ after the CIT.

\section{Triple-Layer Impression Technique}

The subjects were positioned in an upright and comfortable sitting position [6,10-11]. The tray was custommade to suit this technique and tried on the subjects. The markings were highlighted on the same landmarks mentioned previously. Alginate was manipulated according to the manufacturer's instructions and loaded in a $50 \mathrm{~mL}$ syringe. The material was injected from the pra region, then from the poa region, and extending up to the infeoantero border of the earlobe (Figure 4). When the first layer

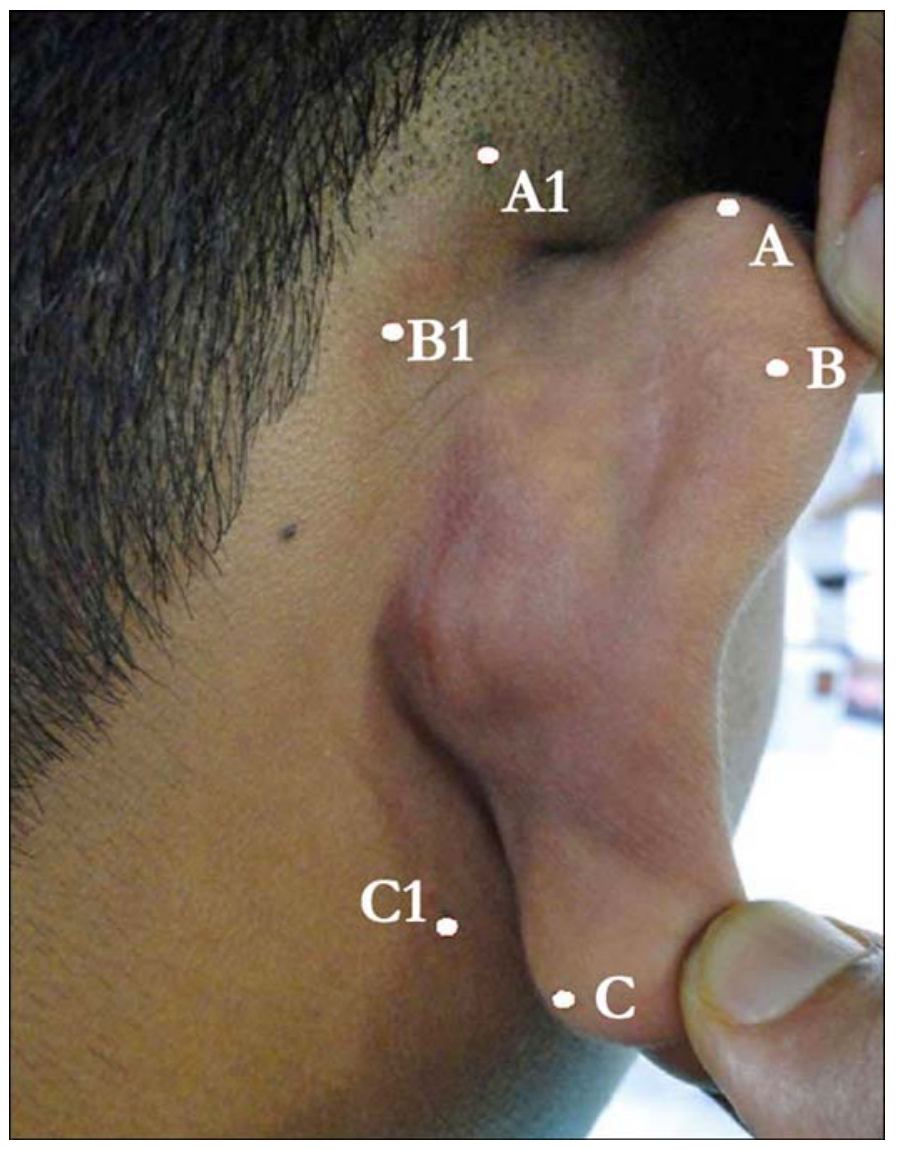

Figure 3.

Markings on ear to measure mediolateral distortion.

Table 1.

Description of landmarks on ear.

\begin{tabular}{ll}
\hline Point & \multicolumn{1}{c}{ Landmark } \\
\hline A & Prominent point of inner side of helix behind super aurale. \\
A1 & Point on skin over temporal bone parallel to point A. \\
B & Prominent point of inner side of helix behind post aurale. \\
B1 & Point on skin over temporal bone parallel to point B. \\
C & Prominent point of inner side of earlobe behind sub aurale. \\
C1 & Point on skin over temporal bone parallel to point C. \\
\hline \hline
\end{tabular}

had its initial set, the second layer was injected into the complex anatomy of the ear, including the tragus, pra region, and external surface of the ear (Figure 5). Subsequently, the third layer of impression material was partially filled into the tray and placed on the ear (Figure 6). The borders of the tray had passive contact with the skin around the ear. The remaining impression material was added to fill the superior aspect of the tray. After the third layer was set, the inferior aspect of the tray was relieved with fingers and lifted to support the impression material. The impression 


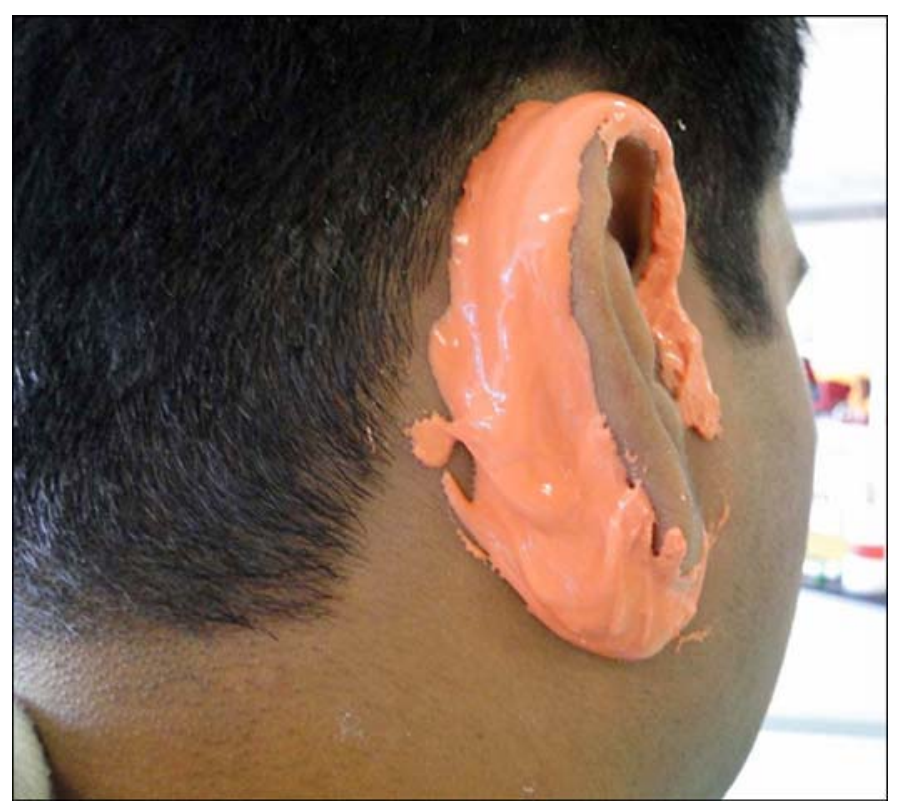

Figure 4.

Triple-layer impression technique of post aurale region (first layer).

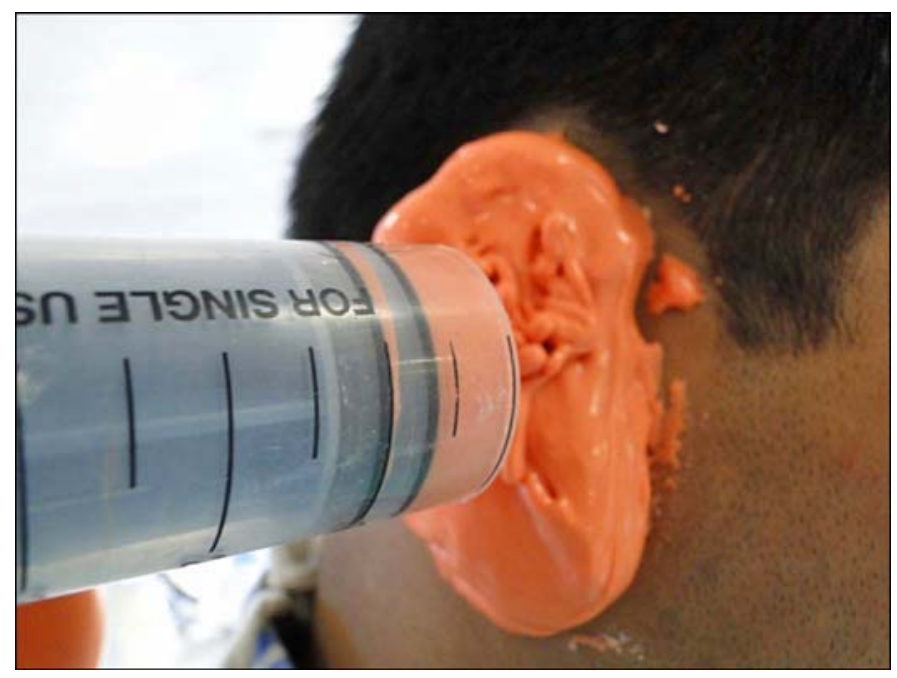

\section{Figure 5.}

Triple-layer impression technique of internal surface of ear (second layer).

was then carefully retrieved. After removal, we ensured that the markings were transferred to the impression (Figure 7).

Models prepared with type IV gypsum (Orthokal, Kalabhai; Mumbai, India) were retrieved from the impression surface, which was separated as three layers (Figure 8). All models were checked for markings, voids, and nodules.

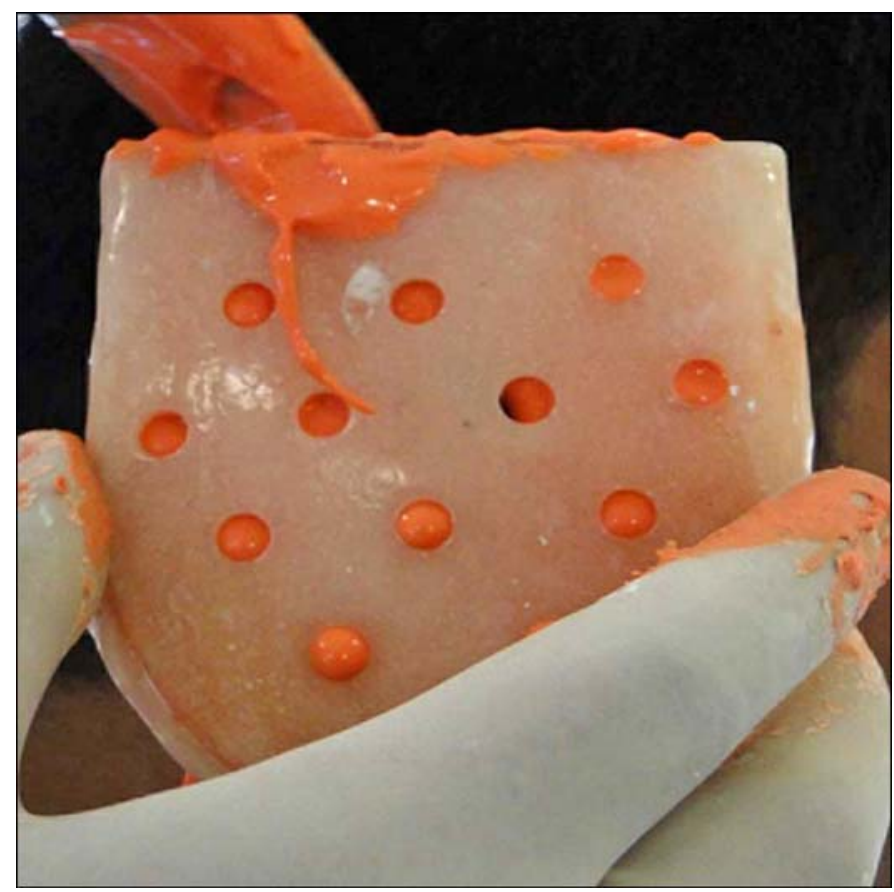

Figure 6.

Triple-layer impression technique (third layer).

The markings were accentuated by highlighting the center point on the marked area (Figure 9). The measurements that were recorded from markings on the ear were rechecked on both models obtained from the different impression techniques in the same order and results were tabulated.

The statistical analysis was performed using SPSS version 16.0 (IBM Corporation; Armonk, New York). Mean \pm standard deviation and distribution analysis were performed to evaluate the distribution of difference between the measurements made on the subject's ear and the measurements made on the models obtained from two impression techniques. Table 2 shows the differences in length; width; and A-A1, B-B1, and C-C1 values. Sign test was done to evaluate the statistical significance of the differences in length; width; and A-A1, B-B1, and C-C1 values on the subject's ear and the measurements made on models obtained from the two impression techniques.

\section{RESULTS}

Distribution of differences (Table 2) shows that the dimensions in length and width obtained from TLIT were closer to subjects' actual dimensions. This was evident 


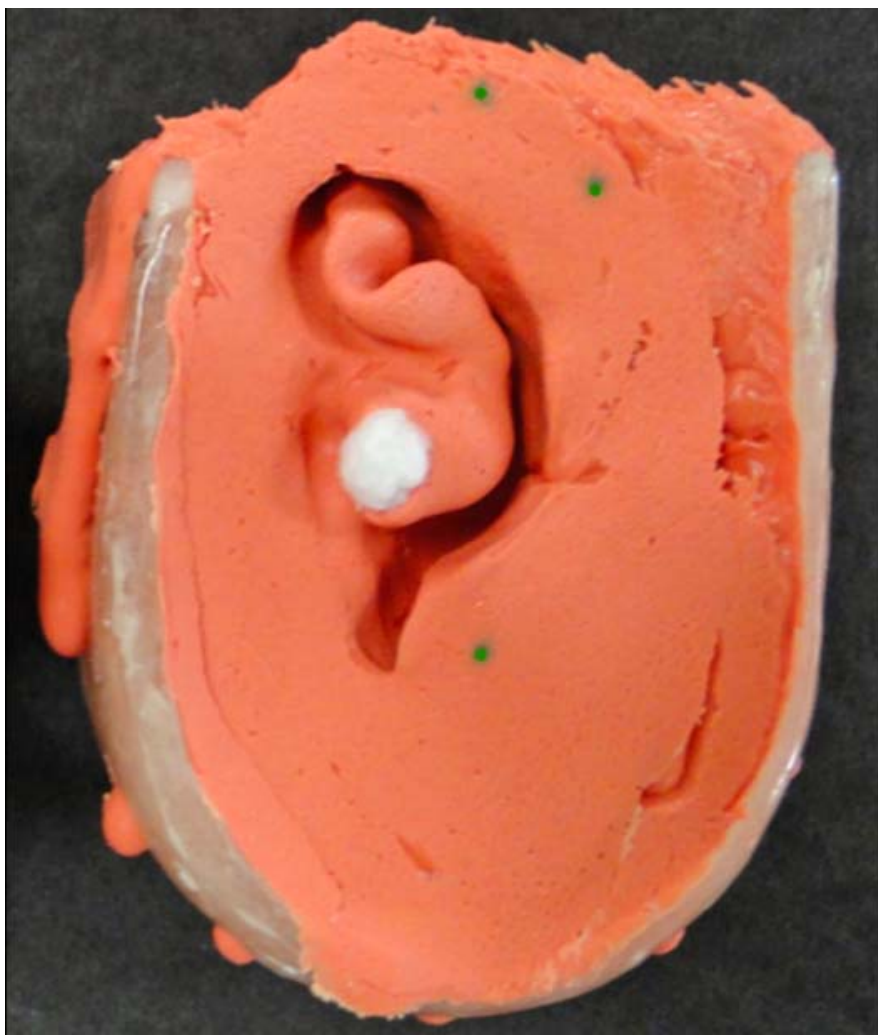

Figure 7.

Triple-layer impression technique: transferred markings on impression surface.

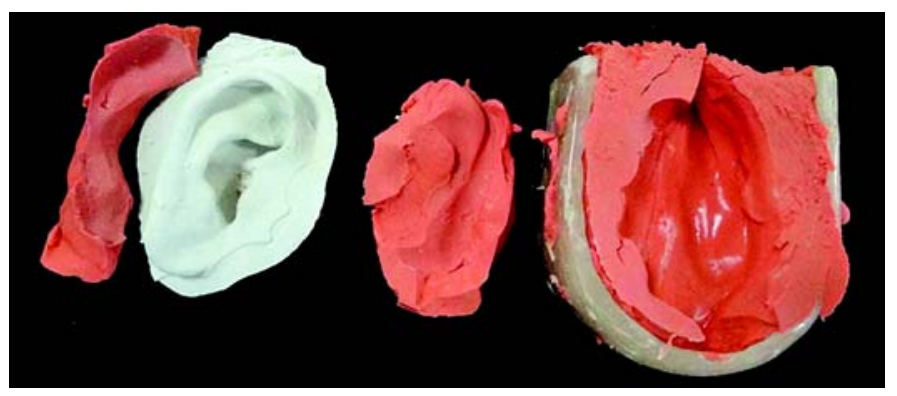

\section{Figure 8.}

Triple-layer impression technique: model retrieved from layers of impression.

by the number of zeros among the differences between subject and TLIT values when compared with differences between subject and CIT values (Table 2). However, the difference in length and width between the two techniques when compared with subjects' actual dimensions was statistically insignificant.

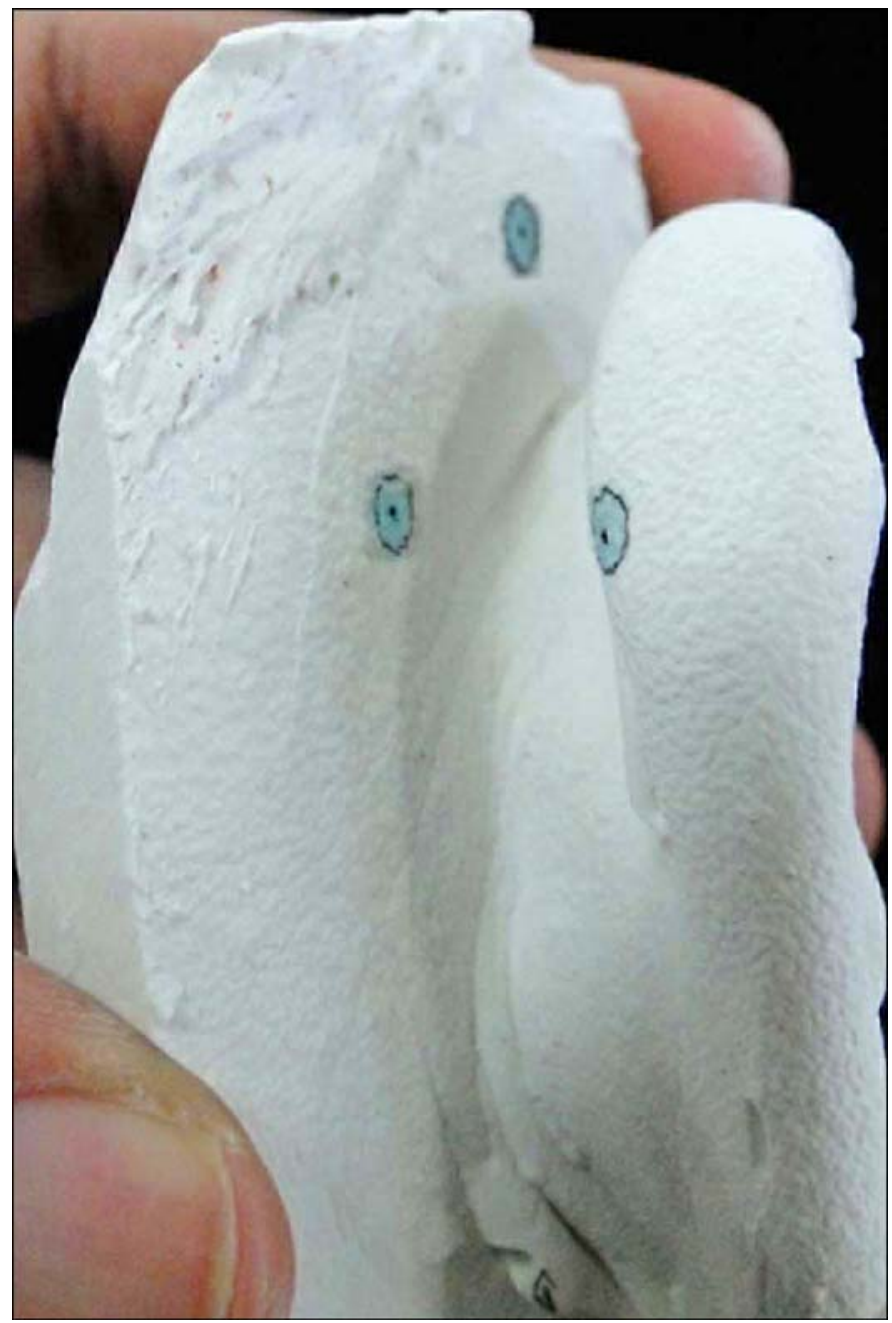

Figure 9.

Transferred markings highlighted on model.

Distribution of differences in A-A1, B-B1, and C-C1 measurements between the two impression techniques shows that dimensions on models made from TLIT were closer to subjects' actual dimensions. This was evident by more zeros in difference between subject and TLIT measurements given in Table 2. The difference was statistically significant $(p<0.01)$ in all three dimensions.

\section{DISCUSSION}

Accurate reproduction of the morphology of the ear is essential for orientation of the wax pattern during the try-in stage in order to reduce chairside time and patient 
JRRD, Volume 50, Number 8, 2013

Table 2.

Distribution analysis of differences between two impression techniques with subject measurements. See Table $\mathbf{1}$ for description of landmarks.

\begin{tabular}{|c|c|c|c|c|c|c|c|c|c|c|}
\hline Subject & \multicolumn{2}{|c|}{ Length (mm) } & \multicolumn{2}{|c|}{ Width (mm) } & \multicolumn{2}{|c|}{ A-A1 (mm) } & \multicolumn{2}{|c|}{ B-B1 (mm) } & \multicolumn{2}{|c|}{ C-C1 (mm) } \\
\hline 1 & -0.20 & 0.10 & 0.00 & 0.00 & -0.10 & -0.10 & 0.20 & 0.00 & 0.60 & 0.10 \\
\hline 3 & 0.00 & 0.00 & 0.40 & 0.50 & 0.10 & 0.00 & -0.10 & 0.00 & 0.30 & 0.10 \\
\hline 4 & -0.20 & 0.20 & 0.10 & 0.00 & 0.00 & -0.10 & 0.20 & -0.10 & 0.50 & 0.10 \\
\hline 5 & 0.00 & 0.00 & 0.10 & 0.10 & 0.30 & 0.00 & 0.10 & -0.10 & 0.20 & 0.00 \\
\hline 7 & 0.10 & -0.10 & 0.10 & 0.10 & 0.30 & 0.00 & 0.10 & 0.00 & 0.50 & 0.00 \\
\hline 8 & 0.00 & 0.00 & 0.00 & 0.00 & 0.20 & 0.00 & 0.30 & 0.00 & 0.40 & -0.10 \\
\hline 9 & 0.00 & 0.00 & 0.00 & 0.00 & 0.20 & 0.10 & 0.10 & 0.10 & 0.10 & 0.40 \\
\hline 10 & 0.00 & -0.10 & 0.00 & -0.10 & 0.10 & 0.00 & 0.00 & -0.10 & 0.20 & 0.00 \\
\hline 11 & 0.00 & 0.00 & 0.00 & 0.00 & 0.20 & 0.00 & 0.10 & 0.10 & 0.00 & -0.10 \\
\hline Mean \pm SD & $-0.007 \pm 0.088$ & $0.007 \pm 0.0799$ & $0.040 \pm 0.1242$ & $0.040 \pm 0.1352$ & $0.153 \pm 0.1302$ & $-0.013 \pm 0.0516$ & $0.147 \pm 0.1457$ & $-0.013 \pm 0.0640$ & $0.393 \pm 0.2939$ & $0.047 \pm 0.1302$ \\
\hline $\begin{array}{l}\text { Sign Test } \\
\text { ( } p \text {-value) }\end{array}$ & & & & $00^{*}$ & & $000^{\dagger}$ & & $006^{\dagger}$ & & $001^{\dagger}$ \\
\hline \multicolumn{11}{|c|}{$\begin{array}{l}\text { *Nonsignificant. } \\
{ }^{*} \text { Significant }(p<0.01) .\end{array}$} \\
\hline
\end{tabular}

and operator fatigue [12]. Several materials have been used to obtain the moulage impression, including plaster, reversible hydrocolloid, irreversible hydrocolloid, and elastomeric materials such as polyvinylsiloxane and polysulfide rubber. Elastomeric impression materials have shortcomings such as short working time, the need for a large quantity of material to record extensive defects, and relatively high cost [13].

A single component impression material with higher tear strength could cause severe trauma to the tissues during retrieval of the set impression. Making an impression of both the expanded ear and the contours of the helix would require the impression to bend around the helix; hence, irreversible hydrocolloid or alginate is most commonly used when making an auricular impression [14]. It is used more frequently because it is readily available in the dental office, is inexpensive, has a long shelf life, provides good detail reproduction, and has satisfactory physical properties [13].

The CIT [9] for auricular prosthesis distorts the ear due to the weight of the irreversible hydrocolloid impression material and patient position during impression making [5]. One of the major intricacies in the CIT is that the inner side of the earlobe is not accurately reproduced, especially in the crura of the antihelix region and crus of the helix [15].

The TLIT described here has several advantages over the CIT. The primary advantage to the TLIT is less distortion of the ear. Other advantages to this technique include easy retrieval of the model from the three layers of impression surface, easy retrieval of the wax pattern prepared from the impression surface of the donor technique, and less voids while recording the impression of the internal surface of the external ear. Usually, techniques for obtaining impressions of partial defects are generally the same as for the total defect. However, care should be taken to ensure that any unsupported tissue remnant is not distorted during the process. Consideration should be made with regard to the volume of impression material applied to the remnant because the weight of the material may cause distortion [11]. Soft tissue distortion is less because of the absence of an overlying stone matrix that is present in the CIT [2]. TLIT made with subjects in the upright position meets the previously mentioned concerns. 
In any treatment mode selected for patients with a unilateral missing ear, dimensional measurements of the existing normal ear and its position, level, and prominence are needed to plan the siting and shaping of the reconstructed ear or prosthesis. Anthropometric measurements have been used previously to assess dimension, location, inclination, and level of an ear on the normal side in order to construct a prosthetic ear [16].

In this study, 10 anthropometric landmarks were used to evaluate the exact dimensions obtained from two impression techniques. Statistical analyses failed to indicate strong evidence that either impression technique resulted in better accuracy with respect to length and width, whereas statistically significant $p$-values $(<0.01)$ were obtained in $\mathrm{A}-\mathrm{A} 1, \mathrm{~B}-\mathrm{B} 1$, and $\mathrm{C}-\mathrm{C} 1$ values, indicating that TLIT values were closer to subjects' measurements. Perhaps it should be noted that the CIT approach seems to systematically overestimate some of the dimensions, which may be attributed to patient position and the weight of the material during impression making. Thus, adopting TLIT ensured less distortion of the ear and more accurate models. In most patients with unilateral ear defects, when a CIT was used to make an ear, orientation of the wax pattern took at least 2 to $3 \mathrm{~h}$ due to increased distortion. When TLIT was adopted in patients, it helped orient the wax pattern sooner than with CIT. There was an approximate difference of $1 \mathrm{~h}$ between the two techniques in the wax try-in appointment. However, the exact time difference cannot be determined because it differs with each patient's clinical scenario.

Several other impression techniques have been used, such as (1) using the donor technique [3], in which the patient acts as the donor to make an ear impression; (2) dividing the cast of the remaining ear into small squares to facilitate sculpting the missing ear [3,17]; (3) using image-editing software (such as Adobe Photoshop) to assist in sculpting the prosthesis [13,17]; (4) using a color slide [17-18]; (5) obtaining a mirror image of the cast of the patient's remaining ear, using transparent sheets and a copy machine to aid in the sculpting process [17,19]; and (6) sectioning the wax pattern of the opposite ear, using a wax saw, into $1 \mathrm{~mm}$-thick slices, then reversing each section and placing it on top of the previous one to create a mirror image of the original pattern [13,17].

Although some of these methods are rather simplistic, the final outcome of the prosthesis depends on the artistic skill of the maxillofacial prosthetist, especially in sculpting and orienting the wax pattern.
In the last few years, several noncontact methods have been used to produce dimensionally accurate wax ears by rapid prototyping using imaging techniques like computerized tomography (CT), magnetic resonance imaging (MRI), and laser scan (LS) data [16]. These methods are expensive and technique sensitive, especially CT, which is an invasive technique not considered ethical by some groups of professionals and of limited use in developing countries. The present study does not include comparisons between TLIT and noncontact techniques such as CT, MRI, and LS. However, Coward et al. state that there were no statistically significant differences between the measurements made from casts, natural ears, CT, MRI, and LS image [16].

The TLIT explained in this study is a tailor-made, cost-effective, chairside alternative to other impression techniques to produce an accurate cast and wax pattern for auricular prostheses. It enables the maxillofacial prosthetist to achieve proper orientation of the unilateral auricular prosthesis, reducing the distortion level. However, it is sometimes difficult to handle the alginate while making the impression, especially in the poa region; manipulation according to the prescribed water-powder ratio can alleviate this problem. TLIT is a little more time consuming than CIT. The average time for CIT is $12 \mathrm{~min}$ and the average time for TLIT is $18 \mathrm{~min}$, with a difference of approximately $6 \mathrm{~min}$. TLIT lengthens the impression-making time, but spending an extra few minutes during impression considerably reduces the orientation of the wax pattern by at least $1 \mathrm{hr}$.

\section{CONCLUSIONS}

Within the limitations of this pilot study, we found TLIT to be an economic, simple technique for fabricating unilateral auricular prostheses. The distortion in TLIT was significantly less than CIT at $p<0.01$. The TLIT was primarily put forth to preclude the use of expensive and technique-sensitive methods used to prepare the model for ear prostheses and to make it more affordable to patients, especially in developing countries. However, further investigations on a larger sample size are required to validate the results of this technique. 


\section{ACKNOWLEDGMENTS}

\section{Author Contributions:}

Study concept and design: K. Mohamed.

Acquisition of data: M. K. Seenivasan, U. M. Mani.

Analysis and interpretation of data: K. Mohamed, U. M. Mani,

M. K. Seenivasan.

Drafting of manuscript: K. Mohamed, U. M. Mani.

Critical revision of manuscript for important intellectual content:

K. Mohamed, U. M. Mani.

Statistical analysis: K. Mohamed, M. K. Seenivasan.

Administrative, technical, or material support: P. T. Veeravalli,

A. K. Vaidhyanathan.

Study supervision: P. T. Veeravalli, A. K. Vaidhyanathan.

Financial Disclosures: The authors have declared that no competing interests exist.

Funding/Support: This material was unfunded at the time of manuscript preparation.

Additional Contributions: We acknowledge Dr. Mark F. Mathews for his original concept of using the syringe technique for auricular impressions. We also acknowledge Dr. Bhakti Jain and Dr. Ahmed Jibran, postgraduate students, for their contribution in conducting this study. Institutional Review: This study was approved by the Sri Ramachandra University Institutional Ethics Committee (IEC-NI/11/AUG/24/36). Participant Follow-Up: The authors do not plan to inform participants of the publication of this study. However, participants have been encouraged to check the study Web site for updated publications.

\section{REFERENCES}

1. Wang R. Preoperative auricular wax pattern duplication for surgical template fabrication. J Prosthet Dent. 1999;81(5): 634-37. [PMID:10220672]

http://dx.doi.org/10.1016/S0022-3913(99)70222-2

2. Mathews MF, Sutton AJ, Smith RM. The auricular impression: An alternate technique. J Prosthodont. 2000;9(2): 106-9. [PMID:11070140] http://dx.doi.org/10.1111/j.1532-849X.2000.00106.X

3. Beumer J, Ma T, Marunick M, Roumanas E, Nishimura R. Restoration of facial defects: Etiology, disability, and rehabilitation. In: Beumer J, Curtis TA, Marunick MT, editors. Maxillofacial rehabilitation: Prosthodontic and surgical considerations. St. Louis (MO): Ishiyaku EuroAmerica; 1996. p. 337-453.

4. Scaaf NG, Kielich M. Implant-retained facial prostheses. In: Mckinstry RE, editor. Fundamentals of facial prosthetics. Arlington (VA): ABI Professional Publications; 1995. p. 169-79.

5. Wolfaard JF, Coss P, Levesque R. Craniofacial osseointergration: technique for bar and acrylic resin substructure construction for auricular prosthesis. J Prosthet Dent. 1996; 76(6):603-7. [PMID:8957785] http://dx.doi.org/10.1016/S0022-3913(96)90437-0
6. Kubon TM, Anderson JD. An implant-retained auricular impression technique to minimize soft tissue distortion. J Prosthet Dent. 2003;89(1):97-101. [PMID:12589298] http://dx.doi.org/10.1067/mpr.2003.16

7. Wang RR, Andres CJ. Hemifacial microsomia and treatment options for auricular replacement: A review of the literature. J Prosthet Dent. 1999;82(2):197-204. [PMID:10424984] http://dx.doi.org/10.1016/S0022-3913(99)70156-3

8. Ngeow WC, Aljunid ST. Craniofacial anthropometric norms of Malays. Singapore Med J. 2009;50(5):525-28. [PMID:19495526]

9. Chalian VA, Drane JB, Metz HH, Roberts AC, Standish SM. Extraoral prosthetics. In: Chalian VA, Drane JB, Standish SM. Maxillofacial prosthetics; multidisciplinary practice. Baltimore (MD): Williams \& Wilkins Co; 1971. p. 308-10.

10. Kubon TM. Creating an adaptable anterior margin for an implant-retained auricular prosthesis. J Prosthet Dent. 2001; 86(3):233-40. [PMID:11552160] http://dx.doi.org/10.1067/mpr.2001.118019

11. Thomas KF. Impression materials and techniques. In: The art of clinical anaplastology. England: S. Thomas; 2006. p. 29.

12. Mekayarajjananonth T, Huband ML, Guerra LR. Clear acrylic resin device for orientation and placement of a small facial prosthesis. J Prosthet Dent. 2000;83(6):656-59. [PMID:10842134]

13. Andres CJ, Haug SP. Facial prosthesis fabrication: Technical aspects. In: Taylor TD, editor. Clinical maxillofacial prosthetics. Chicago (IL): Quintessence Publishing Co; 2000. p. 233-44.

14. Kubon TM, Kurtz KS, Piro JD. Impression procedure for creating a partial auricular prosthesis. J Prosthet Dent. 2000; 83(6):648-51. [PMID:10842132]

15. Seelaus R, Troppmann RJ. Facial prosthesis fabrication: Coloration technique. In: Taylor TD, editor. Clinical maxillofacial prosthetics. Chicago (IL): Quintessence Publishing Co; 2000. p. 245-64.

16. Coward TJ, Scott BJ, Watson RM, Richards R. A comparison between computerized tomography, magnetic resonance imaging, and laser scanning for capturing 3-dimensional data from a natural ear to aid rehabilitation. Int J Prosthodont. 2006;19(1):92-100. [PMID:16479767]

17. Al Mardini M, Ercoli C, Graser GN. A technique to produce a mirror-image wax pattern of an ear using rapid prototyping technology. J Prosthet Dent. 2005;94(2):195-98. [PMID:16046973] http://dx.doi.org/10.1016/j.prosdent.2005.04.019

18. Shimodaira K, Fukuda H, Kanazawa T, Funakubo T. Technique for superimposing a color slide onto a facial cast to sculpt a facial prosthesis. J Prosthet Dent. 1989;62(2):212-13. [PMID:2760862] http://dx.doi.org/10.1016/0022-3913(89)90316-8 
19. Lemon JC, Chambers MS, Wesley PJ, Martin JW. Technique for fabricating a mirror-image prosthetic ear. J Prosthet Dent. 1996;75(3):292-93. [PMID:8648577] http://dx.doi.org/10.1016/S0022-3913(96)90487-4

Submitted for publication August 9, 2012. Accepted in revised form January 17, 2013.

This article and any supplementary material should be cited as follows:
Mohamed K, Mani UM, Seenivasan MK, Vaidhyanathan AK, Veeravalli PT. Comparison of two impression techniques for auricular prosthesis: Pilot study. J Rehabil Res Dev. 2013;50(8):1079-88.

http://dx.doi.org/10.1682/JRRD.2012.08.0145

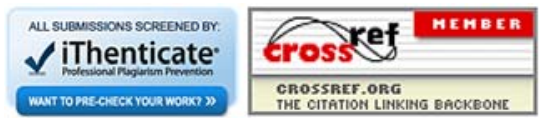


